\title{
PROFILE OF SKIN CHANGES AND ITS ASSOCIATION WITH BIOCHEMICAL PARAMETERS IN HAEMODIALYSIS PATIENTS
}

\author{
Pallavi Bakthavatchalu1, Ashwini Padubidri Kombettu2, Jayadev Betkerur ${ }^{3}$, Kushalappa P. $A^{4}$, Chetan C. $S^{5}$ \\ 1 Junior Resident, Department of Dermatology, Venereology and Leprosy, JSS Medical College, JSS University, Mysuru. \\ ${ }^{2}$ Assistant Professor, Department of Dermatology, Venereology and Leprosy, JSS Medical College, JSS University, Mysuru. \\ 3 Professor and HOD, Department of Dermatology, Venereology and Leprosy, JSS Medical College, JSS University, Mysuru. \\ 4 Professor, Department of Dermatology, Venereology and Leprosy, JSS Medical College, JSS University, Mysuru. \\ ${ }^{5}$ Assistant Professor, Department of Nephrology, JSS Medical College, JSS University, Mysuru.
}

\begin{tabular}{l}
\hline ABSTRACT \\
BACKGROUND \\
A multitude of skin changes are seen in haemodialysis (HD) patients. Various biochemical changes occur in patients on HD. \\
The objectives of the study were to describe the pattern of cutaneous manifestations and its association with biochemical parameters \\
in patients with Chronic kidney disease (CKD) on HD.
\end{tabular}

\section{MATERIALS AND METHODS}

In a descriptive study, patients who underwent HD at least twice a week for minimum three months were included. Investigations like haemoglobin, serum levels of urea, creatinine, calcium, phosphorus and parathormone were done.

\section{RESULTS}

62 patients with CKD on haemodialysis were examined for cutaneous changes. The most prevalent findings were xerosis (74\%), pruritus (42\%), diffuse hyperpigmentation (40\%). Other manifestations included acquired perforating disorder (8\%), acrochordon, purpura, acneiform eruptions, vitiligo, lichen simplex chronicus, dermatosis papulosa nigra and eczema. Among the $16 \%$ of patients with cutaneous infections, Herpes zoster (8\%) was the commonest. The nails showed subungual hyperkeratosis (8\%), half and half nails (6\%), Beau's lines (6\%), nail dystrophy, leuconychia, koilonychia and melanonychia. Hair changes included hair loss (24\%) and lustreless hair (9\%). Hyperpigmentation (8\%), bald tongue (4\%), fissured tongue (3\%) were seen in the oral cavity. This study showed a significant association between pruritus and elevated parathormone levels (P value: 0.037) and also between xerosis and elevated serum creatinine levels (P value: 0.026 ).

\section{CONCLUSION}

Various dermatological manifestations are seen in HD patients. In our study, we found a significant association between pruritus and elevated parathormone levels and also between xerosis and elevated serum creatinine levels. An attempt to explain the skin changes associated with haemodialysis is made.

\section{KEYWORDS}

Skin, Parathormone, Creatinine.

HOW TO CITE THIS ARTICLE: Bakthavatchalu P, Kombettu AP, Betkerur J, et al. Profile of skin changes and its association with biochemical parameters in haemodialysis patients. J. Evolution Med. Dent. Sci. 2016;5(97):7120-7124, DOI: 10.14260/Jemds/2016/1612

\section{BACKGROUND}

Skin has been known as a mirror for systemic diseases; chronic kidney disease (CKD) presents with multitude of skin changes CKD is defined as glomerular filtration rate (GFR) less than 60 $\mathrm{mL} /$ minute $/ 1.73 \mathrm{~m}^{2}$ for 3 or more months. ${ }^{1}$ Increase in plasma levels of urea and creatinine begin when GFR falls to $50 \%$. CKD is classified into five stages. Patients with end-stage renal disease (ESRD) require either haemodialysis or peritoneal dialysis or renal transplant to ward off complications. Patients on HD develop cutaneous manifestations which may be the

Financial or Other, Competing Interest: None.

Submission 30-10-2016, Peer Review 23-11-2016,

Acceptance 29-11-2016, Published 05-12-2016.

Corresponding Author:

Pallavi Bakthavatchalu,

Department of Dermatology,

JSS Medical College and Hospital,

JSS University, Mahatma Gandhi Road,

Mysuru - 570004

Karnataka, India.

E-mail: naidu.pallavi@gmail.com

DOI: $10.14260 /$ jemds/2016/1612 markers for biochemical or organic changes in the body. Pico et $\mathrm{al}^{2}$ and Udaykumar et $\mathrm{al}^{3}$ reported that $100 \%$ of patients on dialysis develop cutaneous manifestations. Some of them like nephrogenic fibrosing dermopathy and dialysis porphyria develop only following initiation of dialysis. ${ }^{4}$ Abnormalities in biochemical parameters like urea, creatinine, parathormone, calcium, phosphorus levels occur early in CKD. Our study was conducted to describe the pattern of cutaneous manifestations in patients with CKD on haemodialysis and to find the association between biochemical changes and cutaneous manifestations in patients on HD.

\section{MATERIALS AND METHODS}

This was a descriptive study conducted from November 2013 to May 2015 involving patients who had completed at least 3 months of haemodialysis at JSS Medical College and Hospital, Mysuru, India. The study was cleared by institutional ethical committee. An informed written consent was obtained from all patients. A detailed history and clinical examination was done. Blood investigations like blood urea, serum creatinine, calcium, phosphorus and parathormone levels were done. 
Potassium hydroxide preparation, fungal culture, skin biopsy were done as and when necessary.

\section{Sample Size}

This study involves patients who have completed 3 months of haemodialysis; considering the factors like dropouts and deaths, our sample size was 60 .

\section{Sampling Technique}

Consecutive sampling.

\section{Statistical Analysis}

- Descriptive statistics - The descriptive procedure displays univariate summary statistics for several variables in a single table and calculates standardised values (z scores). Variables can be ordered by the size of their means (in ascending or descending order), alphabetically or by the order in which we select the variables (default).

- Chi-square test - The Chi-Square test procedure tabulates a variable into categories and computes a chi-square statistics. This goodness-of-fit test compares the observed and expected frequencies in each category to test either that all categories contain the same proportion of values or that each category contains a user-specified proportion of values. This test was done to find out an association between biochemical changes and cutaneous manifestations.

All statistical methods were carried out through SPSS for Windows (version 18.0).

\section{Inclusion Criteria}

- Patients $>18$ years.

- All patients with CKD on haemodialysis for more than 3 months.

- Patients who are on dialysis twice/thrice a week.

- Patients who are dialysed through arteriovenous fistula/ arteriovenous graft/Permcath.

\section{Exclusion Criteria}

- Patients noncompliant with the dialysis schedule.

- Pre-existing chronic skin disease.

- Dialysis done through temporary jugular catheter.

- Associated malignancy.

\section{RESULTS}

Sixty two patients (51 males, 11 females) were examined for skin lesions. All sixty two patients $(100 \%)$ on haemodialysis had at least one cutaneous manifestation. Most of the patients were in the age group of 51-60 years $(n=19)$ and the least number of patients $(n=8)$ belonged to age group of $31-40$ years. Duration of dialysis was in the range of 3 months to 6 years. Frequency of dialysis was twice or thrice a week, majority of patients underwent dialysis twice a week $(n=48)$. The most common cause of CKD was diabetic nephropathy $(n=41)$, other causes were chronic glomerulonephritis, chronic interstitial nephritis, polycystic kidney disease. The various cutaneous manifestations observed in our study are shown in Figure 1. The commonest skin finding in our study was xerosis (Figure 2a) seen in $74 \%$ followed by pruritus (42\%). Pallor was seen in $45 \%$ of patients. Diffuse hyperpigmentation (Figure $2 \mathrm{~b}$ ) was documented in $40 \%$ of patients.

Cutaneous infections were seen in $16 \%$ of patients; Herpes zoster (Figure 2c) was the commonest, seen in $8 \%$ of patients.
The other infections seen were folliculitis, tinea versicolor, tinea cruris and onychomycosis. Nail changes included subungual hyperkeratosis (8\%), half and half nails (6\%, Figure 2d), Beau's lines (6\%). Nail dystrophy, leuconychia, koilonychia and melanonychia were seen in few cases. Acquired perforating disorder (Figure 3) was seen in $8 \%$ of patients. Hair changes included hair loss (24\%) and lustreless hair (9\%). Oral manifestations included hyperpigmentation $(8 \%)$, bald tongue $(4 \%)$ and fissured tongue $(3 \%)$.

Skin changes in relation to frequency of dialysis are tabulated in Table 1. In our study, we found a higher incidence of cutaneous manifestations in patients who underwent dialysis twice a week when compared to patients who underwent dialysis thrice a week.

On correlating the biochemical parameters with various cutaneous manifestations, there was a significant association between elevated serum creatinine levels and xerosis (Table 2); also between elevated serum parathormone levels and pruritus (Table 3).

There was no significant association between other biochemical parameters (urea, calcium, phosphorus) with skin changes.

\begin{tabular}{|c|c|c|}
\hline \multirow[b]{2}{*}{$\begin{array}{c}\text { Cutaneous } \\
\text { Manifestations }\end{array}$} & \multicolumn{2}{|c|}{ Frequency of Dialysis } \\
\hline & $\begin{array}{c}\text { Thrice a } \\
\text { Week (\%) }\end{array}$ & $\begin{array}{c}\text { Twice a } \\
\text { Week (\%) }\end{array}$ \\
\hline Pruritus & 15.3 & 84.6 \\
\hline Xerosis & 22 & 78.2 \\
\hline Hyperpigmentation & 28 & 72 \\
\hline Perforating disorder & 20 & 80 \\
\hline Nail changes & 19 & 81 \\
\hline Pallor & 7 & 93 \\
\hline Hair changes & 9 & 91 \\
\hline Mucosal changes & 33.3 & 66 \\
\hline Cutaneous infections & 20 & 80 \\
\hline $\begin{array}{r}\text { Table I. Cutaneous } \\
\text { Freq }\end{array}$ & $\begin{array}{l}\text { festations } \\
\text { of Dialysi }\end{array}$ & on to \\
\hline
\end{tabular}

\begin{tabular}{|c|c|c|}
\hline \multirow{2}{*}{$\begin{array}{c}\text { Cutaneous } \\
\text { Manifestations }\end{array}$} & \multicolumn{2}{|c|}{ Serum Creatinine } \\
\cline { 2 - 3 } $\mathbf{4 - 6 . 9} \mathbf{~ m g} / \mathbf{d L}$ & $\mathbf{7 7} \mathbf{~ m g / d L}$ \\
\hline Pruritus & 4 & 22 \\
\hline Xerosis & 8 & 38 \\
\hline Hyperpigmentation & 6 & 19 \\
\hline Nail changes & 3 & 18 \\
\hline Cutaneous infections & 1 & 9 \\
\hline Hair changes & 2 & 19 \\
\hline Mucosal changes & 3 & 6 \\
\hline Table II. Cutaneous Manifestations in Relation to Serum \\
Creatinine Levels \\
\hline
\end{tabular}

\begin{tabular}{|c|c|c|}
\hline \multirow[b]{2}{*}{$\begin{array}{c}\text { Cutaneous } \\
\text { Manifestations }\end{array}$} & \multicolumn{2}{|c|}{ Serum parathormone } \\
\hline & $\begin{array}{c}10-55 \\
\mathrm{pmol} / \mathrm{L}\end{array}$ & $>55 \mathrm{pmol} / \mathrm{L}$ \\
\hline Pruritus & 3 & 23 \\
\hline Xerosis & 3 & 43 \\
\hline Hyperpigmentation & 1 & 24 \\
\hline Nail changes & 1 & 20 \\
\hline Cutaneous infections & 0 & 10 \\
\hline Hair changes & 1 & 20 \\
\hline Mucosal changes & 1 & 8 \\
\hline $\begin{array}{r}\text { Table III. Cutaneous } \\
\text { Serum Pa }\end{array}$ & $\begin{array}{l}\text { festations } \\
\text { rmone Le }\end{array}$ & Relation to \\
\hline
\end{tabular}




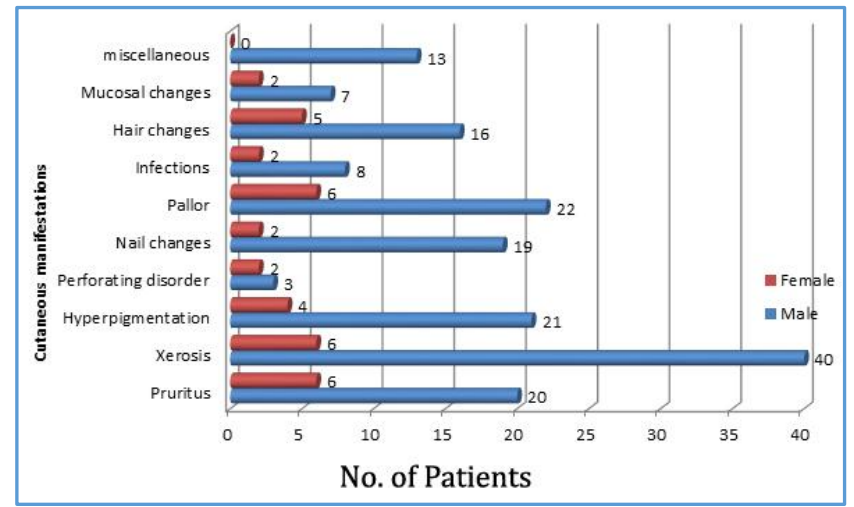

Figure 1. Distribution of Cutaneous Manifestations in Relation to Sex of the Patient

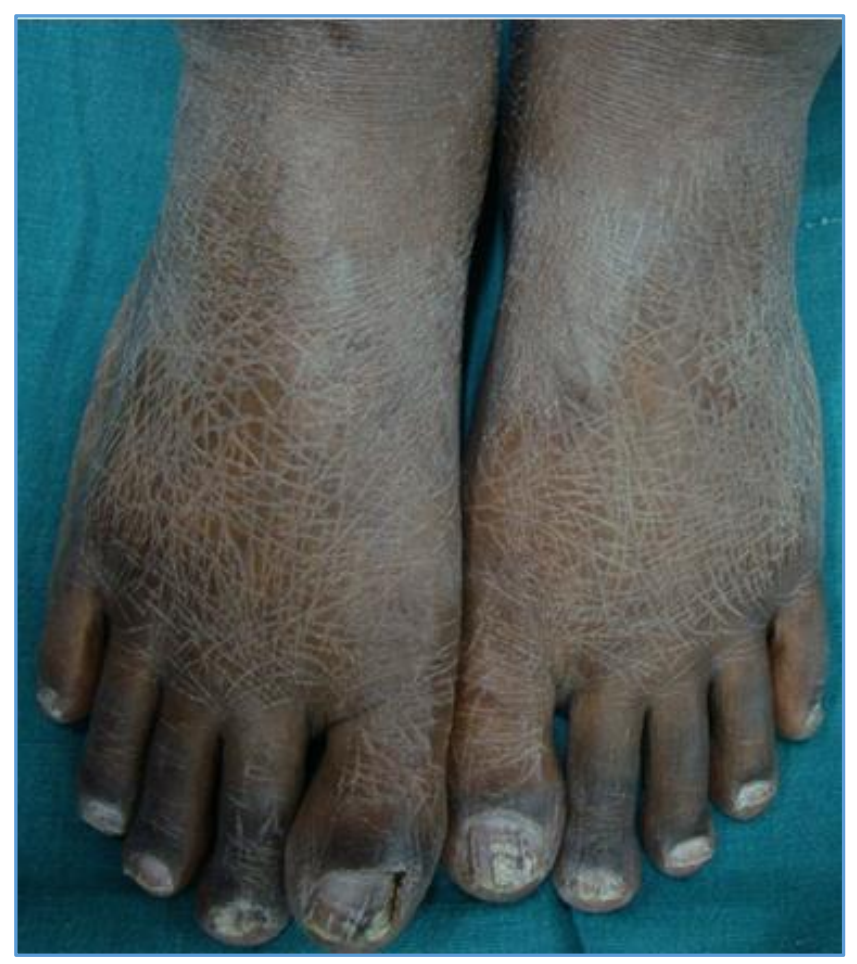

Figure 2a. Xerosis over the Feet with Dystrophic Nails

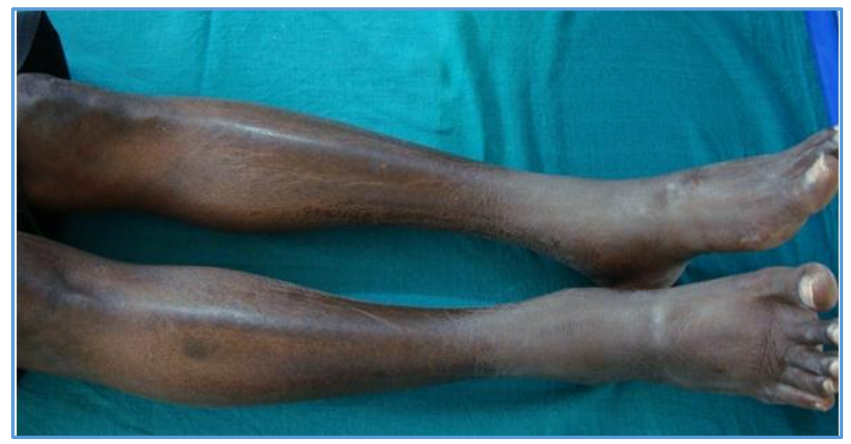

Figure 2b. Hyperpigmentation over Legs

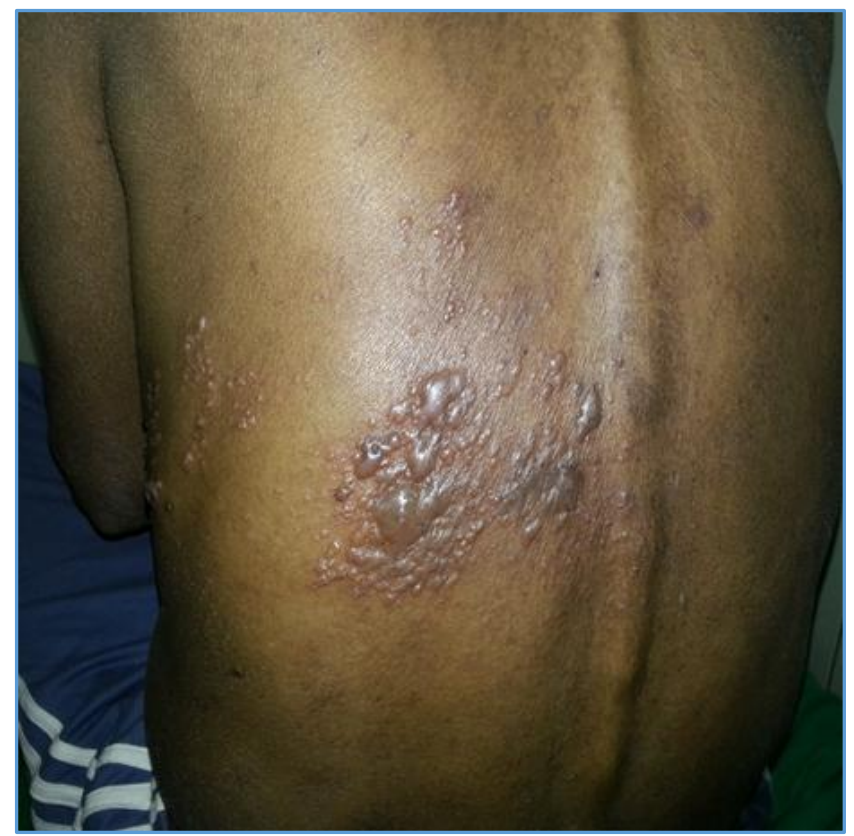

Figure 2c. Herpes Zoster

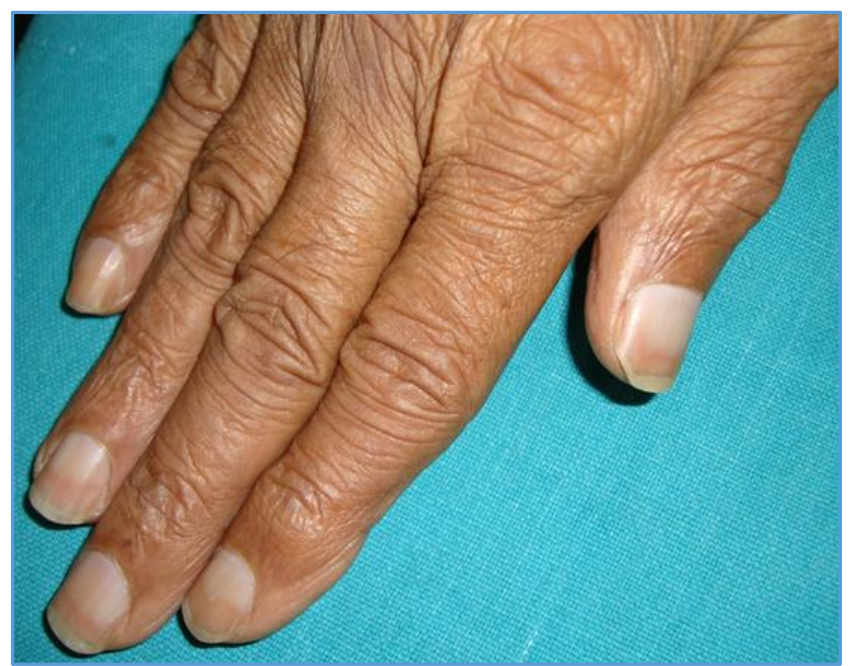

Figure 2d. Half and Half Nails

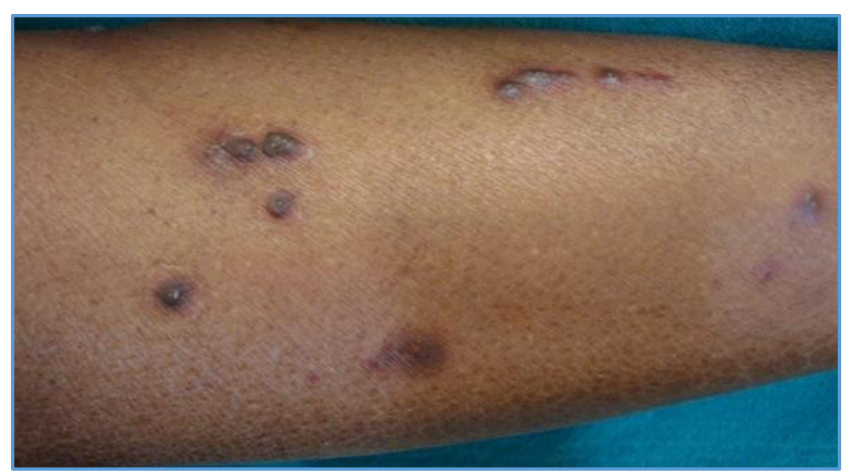

Figure 3. Kyrle's Disease with Koebnerisation 


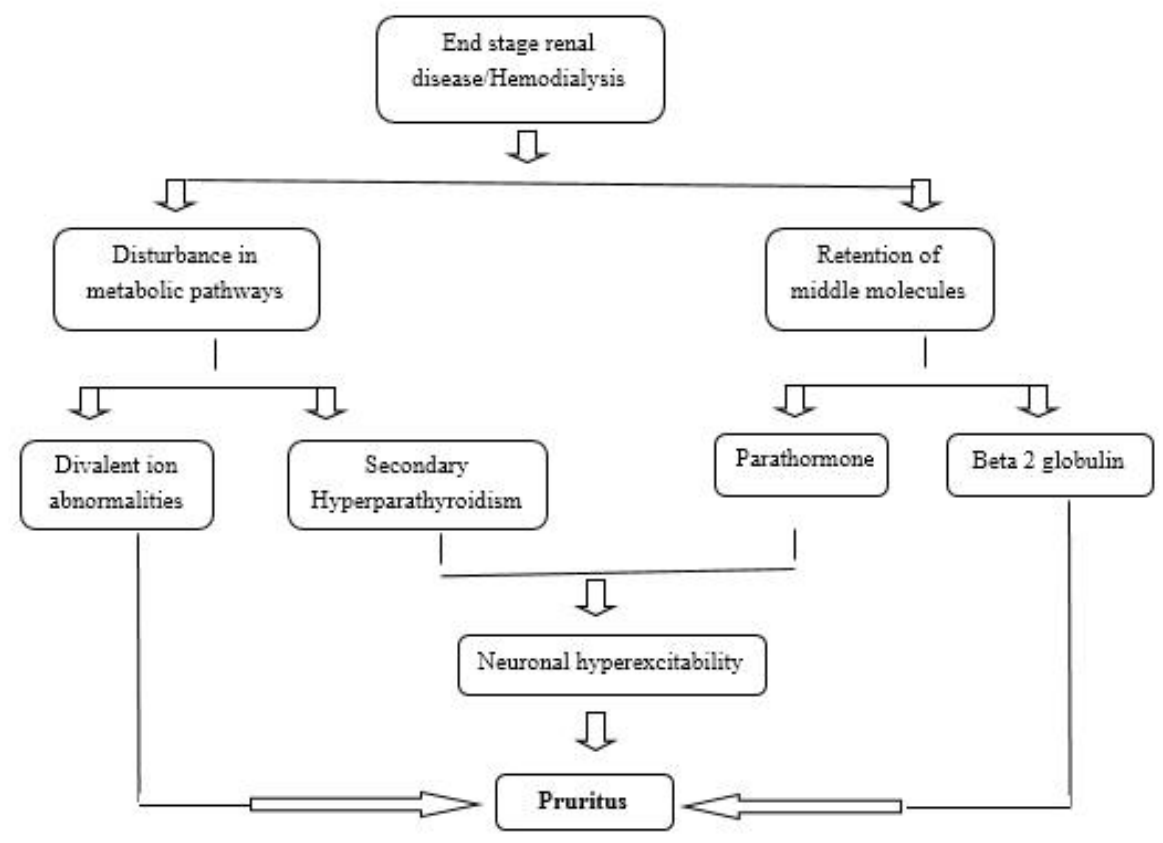

Figure 4. Flowchart Depicting Pathophysiology of Uremic Pruritus

\section{DISCUSSION}

All 62 patients $(100 \%)$ on HD had at least one cutaneous manifestation similar to a study done by Pico et al $^{2}$ and Udaykumar et al. ${ }^{3}$ The preponderance of males $(n=51)$ was in concurrence with findings of a study by Deshmukh et al. ${ }^{4}$

The incidence of cutaneous manifestations was low in patients who underwent dialysis thrice a week when compared to patients who were on dialysis twice a week. This could be due to inadequacy of dialysis leading to skin changes.

Xerosis was the most common cutaneous manifestation in the present study reported in $74 \%(n=46)$ of patients similar to a study by Attia et al. 5 The cause for CKD in 32 out of 46 patients with xerosis was diabetic nephropathy. Few other studies reported an incidence of xerosis in $22.8--90 \%$ of patients. ${ }^{6,7}$ This could be due to reduction in the size of sweat glands, elevated vitamin A levels or drugs (diuretics). ${ }^{2}$

A $42 \%$ incidence of pruritus was documented in our patients similar to other observations. ${ }^{2}$

Diffuse hyperpigmentation was noted in $40 \%$ of patients in the present study. Few other studies reported diffuse hyperpigmentation in $43-75 \%$ of patients.2,3,8 Pigmentation is commonly seen on sun-exposed areas which occurs due to increase in melanin in the basal layer of the epidermis. ${ }^{9}$ Pigmentation in HD patients could also be attributed to betaMelanocyte stimulating hormone. ${ }^{10}$ In our study majority of patients had hyperpigmentation over sun exposed areas.

Pallor was reported in $45 \%$ of patients. Masmoudi et al ${ }^{11}$ reported $60 \%$ incidence of pallor. The cause of anaemia in CKD patients could be due to decreased erythropoietin production or anaemia of chronic disease or nutritional deficiencies. ${ }^{4}$

Nail changes were seen in $34 \%$ of patients. The various nail changes documented in the study are Beau's lines, leuconychia, dystrophic nails, half and half nails, subungual hyperkeratoses, koilonychia and melanonychia. Other nail changes seen in haemodialysis patients such as splinter haemorrhages, Mees lines, Muehrcke's lines ${ }^{3}$ were not seen in our study.
Acquired perforating disorder specifically Kyrle's disease (Figure $1 d$ ) was seen in $8 \%(n=5)$ of patients. The cause of CKD in all patients with perforating disorder was diabetic nephropathy. A study by Hood et al ${ }^{12}$ reported $4 \%$ prevalence of perforating disorder in HD patients.

Mucosal changes were observed in 14\% patients including hyperpigmentation over buccal mucosa, bald tongue and fissured tongue. Hajheydari et $\mathrm{al}^{6}$ though observed similar changes, but reported a higher incidence of $23.8 \%$.

Cutaneous infections were seen in $16 \%$ of patients in the present study. They included herpes zoster, folliculitis, tinea versicolor, tinea cruris and onychomycosis whereas Udaykumar et $\mathrm{al}^{3}$ reported cutaneous infections in 55\% of patients. This difference could not be explained; however, it is possible that the local factors and general hygiene played a part.

The other cutaneous findings observed in the study population were acrochordon, purpura, lichen simplex chronicus, telangiectasias, dermatosis papulosa nigra, eczema, lichenoid eruptions, vitiligo and acneiform eruptions.

None of our patients had other rare manifestations of CRF like calciphylaxis, calcinosis, uremic frost, bullous dermatoses and nephrogenic systemic fibrosis.

There was a significant association ( $\mathrm{p}$ value $=0.037$ ) between pruritus and parathormone levels ( $>55 \mathrm{pmol} / \mathrm{L}$ ); similar to a study by Narita et al $^{13}$ and Stahle-Backdahlm et al ${ }^{14}$ where there was significant elevation of serum parathormone levels in patients with pruritus compared to patients without pruritus. However, few other studies have not shown this association between pruritus and serum PTH levels. ${ }^{15,16,17}$

Pruritus in CKD patients is known as uremic pruritus; however, this entity is not due to elevated blood urea levels. Pruritus is absent in acute renal failure, which implies serum levels of urea and creatinine are not involved in causing uremic pruritus. Various proposed theories for causes of uremic pruritus are secondary hyperparathyroidism, divalention abnormalities (Calcium, phosphorus, magnesium), 
histamine, allergic sensitisation, mast cell proliferation, neuropathy, neurological changes and middle molecule theory. ${ }^{18}$ The various middle molecules evaluated are beta 2 microglobulin, advanced glycosylation end products and parathormone. A flowchart depicting the pathophysiology of pruritus in HD patients is shown in Figure 4.

On correlating parathormone with other cutaneous manifestations, in patient with folliculitis the serum parathormone level was markedly elevated (serum PTH $1036 \mathrm{pmol} / \mathrm{L}$ ). The incidence of hyperpigmentation, nail changes, cutaneous infections, hair changes and mucosal changes increased as the levels of parathormone increased.

The serum calcium levels have been found to be significantly higher in patients with pruritus.13,15 However, others have shown no significant association between pruritus and serum calcium levels. ${ }^{17}$ We observed that in our cases with pruritus the serum calcium levels were either normal or decreased. Many workers have not found any association between serum phosphorus levels and pruritus, which is similar to our observation. ${ }^{16,19}$ But Narita et al reported a significant association between elevated phosphorus levels and pruritus. 13

In our study, there was a significant association between xerosis and elevated serum creatinine levels. Out of 46 patients with xerosis, 38 patients had serum creatinine levels of $>7 \mathrm{mg} / \mathrm{dL}$ which was statistically significant $(\mathrm{p}$ value= 0.026). However, there are no studies correlating xerosis with serum creatinine levels in dialysis patients. The association we found could be an incidental finding. Lack of controls is a limitation in this study.

Identification of skin changes and its association with biochemical changes is pivotal to reduce morbidity and suffering in HD patients, hence further studies correlating the cutaneous manifestations with the biochemical parameters in haemodialysis patients are required.

\section{CONCLUSIONS}

A multitude of skin changes are seen in HD patients. All our 62 patients on haemodialysis showed at least one cutaneous manifestation. Recognising the skin changes is vital as it can aid as a tool in identifying biochemical changes. In our study, we found a significant association between pruritus and elevated parathormone levels. We also found a significant association between xerosis and elevated serum creatinine levels which could be a coincidental finding. Patients with nail changes, folliculitis, hyperpigmentation and hair changes also showed, though not significant, increased serum parathormone levels. Since there is paucity of studies which correlate biochemical changes with specific cutaneous manifestations in patients on HD, our study tries to fill the lacunae which exists.

\section{REFERENCES}

1. Tangri N, Stevens LA, Griffith J, et al. A predictive model for progression of chronic kidney disease to kidney failure. JAMA 2011;305(15):1553-9.

2. Pico MR, Lugo-Somolinos A, Sanchez JL, et al. Cutaneous alterations in patients with chronic renal failure. Int J Dermatol 1992;31(12):860-3.
3. Udayakumar P, Balasubramanian S, Ramalingam KS, et al. Cutaneous manifestations in patients with chronic renal failure on hemodialysis. Indian J Dermatol Venereol Leprol 2006;72(2):119-25.

4. Deshmukh SP, Sharma YK, Dash K, et al. Clinicoepidemiological study of skin manifestations in patients of chronic renal failure on hemodialysis. Indian Dermatol Online J 2013;4(1):18-21.

5. Attia EA, Hassan SI, Youssef NM. Cutaneous disorders in uremic patients on hemodialysis: an Egyptian casecontrolled study. Int J Dermatol 2010;49(9):1024-30.

6. Hajheydari Z, Makhlough A. Cutaneous and mucosal manifestations in patients on maintenance hemodialysis: a study of 101 patients in Sari, Iran. Iran J Kidney Dis 2008;2(2):86-90.

7. Tawade YV, Gokhale BB. Dermatologic manifestations of chronic renal failure. Indian J Dermatol Venereol Leprol 1996;62(3):155-6.

8. Dyachenko P, Monselise A, Shustak A, et al. Nail disorders in patients with chronic renal failure and undergoing haemodialysis treatment: a case-control study. J Eur Acad Dermatol Venereol 2007;21(3):340-4.

9. Griffon-Euvrard S, Bustamante R, Thiovolet J. Skin manifestations in patients with renal chronic renal failure on regular hemodialysis. Med Ibero Lat Am 1976;4(6):40113.

10. Smith AG, Shuster S, Thody AJ, et al. Role of the kidney in regulating plasma immunoreactive beta-melanocyte stimulating hormone. Br Med J 1976;1(6014):874-6.

11. Masmoudi A, Darouiche HM, Salah BH, et al. Cutaneous abnormalities in patients with end stage renal failure on chronic hemodialysis. A study of 458 patients. J Dermatol Case Rep 2014;8(4):86-94.

12. Hood AF, Hardegen GL, Zarate AR, et al. Kyrle's disease in patients with chronic renal failure. Arch Dermatol 1982;118(2):85-8.

13. Narita I, Alchi B, Omori K, et al. Etiology and prognostic significance of severe uremic pruritus in chronic hemodialysis patients. Kidney Int 2006;69(9):1626-32.

14. Stahle-Backdahl M, Hagermark O, Lins LE. Pruritus in patients on maintenance hemodialysis. Acta Med Scand 1988;224(1):55-60.

15. Szepietowski JC. Selected elements of the pathogenesis of pruritus in hemodialysis patients. Med Sci Monit 1996;2:343-7.

16. Akhyani M, Ganji MR, Samadi N, et al. Pruritus in hemodialysis patients. BMC Dermatol 2005;5:7.

17. Tajbakhsh R, Joshaghani HR, Bayzayi F, et al. Association between pruritus and serum concentrations of parathormone, calcium and phosphorus in hemodialysis patients. Saudi J Kidney Dis Transpl 2013;24(4):702-6.

18. Narita I, Iguchi S, Omori K, et al. Uremic pruritus in chronic hemodialysis patients. J Nephrol 2008;21(2):161-5.

19. Mirnezami M, Rahimi H. Factors associated with uremic pruritus in patients undergoing hemodialysis: a report from Arak Valiasr Hospital. Iran J Dermatol 2010;13:12-5. 